Vol. 5, No. 1, 2018

UDC: $658.821: 621-028.63$

D. Tsvok

Researcher

Lviv Politechnic National University

J. Toczynska

$\mathrm{PhD}$, Assistant Professor

Silesian University of Technology (Poland)

\title{
DIGITALIZATION AS A TOOL FOR PROVIDING COMPETITIVE ADVANTAGES TO ENTERPRISES IN THE MACHINE-BUILDING INDUSTRY
}

\begin{abstract}
In such a climate, competition becomes ever more fierce and manufacturers must seize every opportunity and competitive advantage they can find.Increasingly, such advantages-along with new threats of disruption-come from digital technologies. A critical element of manufacturing innovation will be in the form of new business models, particularly regarding services and value-added offerings. In effect, simply making a good product may no longer be enough. Increasingly, what happens after the product is sold looms ever larger. Machine builders that successfully leverage services are using them to drive disruptive new business models that, in effect, enable them to charge for business outcomes-such as plant uptime-just as they now charge for physical products sold as a capital investment.Companies that don't harness services-by converging their service and digital journeys-will risk falling behind in a rapidly changing marketplace in which innovation and agility rule. The author considers digitalization as a basis for service-oriented business models and considers digitalization as a tool for ensuring the competitive advantages of machinebuilding enterprises.
\end{abstract}

Key words: competitive advantage, digitalization, service-oriented business models

\section{Problem statement}

Machine builders in Europe and around the world have long felt the lure of the service-oriented revenue model as a driver of growth and new revenue-one that significantly benefits their enduser manufacturer customers.

European manufacturers are celebrated for the high quality of their products, but a purely product-centric mindset may be a hindrance moving forward. As we will see, they risk falling behind their global competitors in the transition to service-oriented revenue models.

Despite a clear impetus to act, however, only a select few manufacturers have successfully transitioned to service models. We refer to this as the "service dilemma."[15] The gap between the desire for services and their limited success has existed for decades.[16] Machine builders and end users agree strongly on their intention to move into services. However, they acknowledge that in the near term, services will not grow faster than products-a major inhibitor that is slowing the transition to services.

Service Dilemma defined:

1. Manufacturers are challenged to improve profitability

2. They invest in new services

3. New services increase complexity

4. Increased complexity createsprofitability challenges

In effect, the services journey has now converged with the digital business journey. Many 
European manufacturers are in the early stages of connectivity.[17] By accelerating their digital business transformation, they will be able to better navigate complexities of moving to the serviceoriented revenue model with greater ease and speed, less cost, and more effectiveness.

Digital transformation isn't a technology or a product. Rather, it's a philosophy for using digital assets to change the way an organization runs. It involves realigning technology and modifying business processes to better engage employees, customers and other constituents of the extended enterprise. Digital transformation significantly improves the performance and reach of an enterprise and has become a top priority for IT and business leaders across the globe.

Digitization is reshaping the business landscape at an unprecedented rate. The disruption of established businesses used to take decades, but natively digital organizations such as Uber, Google and Amazon have disrupted their respective markets in fewer than 10 years.

\section{Analysis of recent research and publications}

Such prominent economists as M. Porter, A. Thomson, L. Bielykh, A. Yudanov, R. Fatkhudynov, O.Tereshchenko, K. Lemish, E. Andriievska, O. Amosha and others have been studying the problem ofensuring competitive advantage of enterprises. However, these are only fundamental scientific works, which can not always find practical application in modern conditions of competition.

European manufacturing conjures images of modern production facilities churning out some of the finest products in the world-whether from Airbus or Audi, Rolls-Royce or Renault (to name a few). With more than two-thirds of all EU exports coming from manufacturing, the sector continues to be an important engine for growth.[1]

In a recent Cisco survey of executives from both industrial machine builders and enduser manufacturers8 (see "About This Study"), 79 percent of global respondents believe that digital disruption will drive a moderate to major impact at their companies in the next three years. While that figure rises to 90 percent among Asia-Pacific nations (for this survey, China, South Korea, Japan, and India), it falls to
77 percent for European manufacturers (for this survey, Germany, France, Italy, and the United Kingdom)

Rolls-Royce Holdings is a pioneer in transitioning to the service-oriented revenue model. The company, the second-largest manufacturer of aircraft engines, has leveraged its expertise in maintaining and repairing jet engines, while leaving the airlines to their own specialty: flying. In an outcome-based model, Rolls-Royce is paid for continuous uptime, rather than waiting to fix engines once they falter.[13] A key component of this business model is that Rolls-Royce draws more added revenue when the airlines themselves succeed-not when their planes are grounded. As one analyst remarked about Rolls-Royce's TotalCare service, "They aren't selling engines, they are selling hot air out the back of an engine."[14]

\section{The purpose of the article}

The purpose of the article is to highlight the notion of digitalisation as a basis for serviceoriented business models and to reveal the competitive advantages of machine-building enterprises that can be secured through its implementation.

\section{Research materials}

Technology advances often bolster business models that drive innovation, efficiency, sustainability, and cost savings. Such advances in automation are causing many firms to rethink their overall strategy. In particular, the importance of connected products and connected machines in manufacturers' service-oriented strategies-along with the mounting complexity that they bring-is creating new opportunities and challenges.

While many machine builders and end-user manufacturers have a digital agenda, a considerable roadblock is cost, especially amidst decreasing growth and flat-to-down budgets. However, the pace of business is accelerating exponentially. Manufacturers will need to take advantage ofselffunding opportunities. With the pace of business accelerating every day, manufacturers must create a sustained competitive advantage by managing their own disruption and transformation. This requires that they fundamentally change how they operate, with a greater degree of speed. The good news is 
that manufacturers will capture significant value as they further digitize. It is such transformations that can become sources and provide competitive advantages of enterprises (Fig. 1)

Asset Utilization
Predictive Maintenance
Remote Monitoring
Theft Management
Plantwide Wireless
Assembly Line Changeover
Downtime, Idle-time Management

\section{Sustainability}

Energy Management

Quality and Defect Controls

\section{Business Outcomes}

Increase equipment lifespan

Reduce maintenance costs

Reduce cabling costs

Reduce provisioning, clearance, idle times

Reduce time to process orders

\section{Business Outcomes}

Reduce energy consumption

Improve quality

Improve capacity management

Increase operational efficiency

Reduce rework and scrap

\begin{tabular}{|l|l|}
\hline $\begin{array}{l}\text { Supply Chain \& Logistics } \\
\text { Safety Management }\end{array}$ & $\begin{array}{l}\text { Business Outcomes } \\
\text { Reduce accidents } \\
\text { Reduce loss and theft }\end{array}$ \\
\cline { 2 - 2 }
\end{tabular}

\section{Innovation \\ New Product Introduction \\ R\&D Process Optimization \\ Customer Connected Products}

Employee Productivity

Training Management

Visual Factory

Factory Incident Management

\section{Customer Experience}

Production/CRM Integration

Improved Customization

\section{Business Outcomes}

Train efficiently with collaboration solutions

Automate your workforce management

Increase worker mobility

Fig. 1 Sources and factors of formation of competitive advantages of the enterprises of the machine-building industry

In a report by the Global Center for Digital Business Transformation, an IMD and Cisco initiative ("Digital Vortex: How Digital Disruption Is Redefining Industries"), nearly four of the top 10 manufacturing incumbents were considered vulnerable to digital disruption in the next three years. However, 41 percent of manufacturing respondents did not feel that digital disruption was a C-suite concern.[18] Given the threat of disruption, such a lack of concern is clearly a mistake.

ZK Research has interviewed approximately 100 organizations that are aggressively pursuing a digital transformation strategy at varying rates and with different levels of success. Aggressive businesses are transforming the whole 


\section{Tsvok, J. Toczynska}

organization, while other, more conservative ones are only making small, incremental changes. Based on several one-on-one interviews with business and IT leaders, ZK Research draws one significant conclusion: The most successful companies marry strong corporate leadership with digital initiatives and establish a high level of digitization. The more digital an organization is, the more likely it is to pull away from its peers and be a leader in its industry. A proof point of this comes from the book Leading Digital: Turning Technology into Business Transformation by George Westerman, Didier Bonnet and Andrew McAfee, which found that organizations that master digital transformation are $26 \%$ more profitable.

Businesses that choose to embrace digitization will realize a number of business benefits, including the following:

- Capturing new market opportunities: Digitization enables organizations to move much faster than ever before. When new market opportunities arise, a highly digital organization can catch the transition faster than the competition.

- Improved customer experience: Digitization enhances all aspects of the customer journey and can personalize the experience. This improved experience is a key to winning, retaining and growing customers-which is crucial to the long-term success of businesses in this highly competitive era.

- Streamlined business operations: Digitization can streamline processes by removing human latency through automation. Streamlined operations reduce operational costs and enable the staff to be more efficient.

- Extending the reach of the company: Digital technology enables businesses to manage and exploit all forms of digital channels and touch points. Organizations can use these new channels to reach more customers in more places around the globe.

The key theme for digital transformation is speed, as businesses must be able to operate faster than ever. Becoming a digital organization must be a top initiative for every business and IT leader today, as the long-term success of the business depends on it. Digital initiatives are led by technology; however, a significant number of CEOs perceive technology as a key vulnerability for their organizations. The 18th Annual Global CEO Survey conducted by $\mathrm{PwC}$ in 2015 found that $58 \%$ of CEOs expressed anxiety about not being able to change their technology fast enough to keep up with the competition. ZK Research estimates that in 2015, businesses spent $\$ 12$ billion on technology to increase the level of IT agility and evolve into a digital organization. However, the network has yet to evolve. If organizations are to harness the potential of digitization, it's time to evolve the network.

For a company to evolve to a digital organization, IT and business leaders must form a tight partnership. Digitization is possible today because several technologies have matured and have come together at the same time, creating a "perfect storm" scenario:

- Mobile devices: Client evolution has exploded over the past half-decade. What was once deemed impossible to do on a mobile device is now the norm. Web browsing, voice over IP, video conferencing and streaming media are common today on mobile devices because of the evolution of smartphones, tablets and web-optimized laptops.

- Cloud computing: IT managers have been experimenting with cloud computing for a number of years. Today, enough best practices exist to allow enterprises to shift a significant portion of their IT infrastructure to cloud services or to build internal cloud infrastructure.

- Analytics and big data platforms: Digital organizations create terabytes of data, which can be gathered, prepped and analyzed to uncover new business insights. Historically, the big data platforms that used to handle the analytics were very expensive, and only the largest of organizations could deploy them. Today, big data platforms have become more diverse, so companies of all sizes can take advantage of them.

- Internet of Things (IoT): IoT is the networking of physical devices, vehicles, sensors, operational technology (OT) and other objects combined with business process change, data collection and analytics. IoT has the power to streamline process through automation, discover 
new routes to market and significantly reduce costs. ZK Research estimates that IoT will lead to more than 50 billion additional connected devices by 2025 .

One other component of digital transformation that is often overlooked is the network. All of the technology trends listed above are network centric, meaning the network plays a critical role in the success of these initiatives (Exhibit 2).

Unfortunately, few organizations have linked digital transformation to their network. ZK Research has interviewed businesses that have implemented or plan to implement a digital strategy, and the majority have not created a plan to integrate the network into their business strategies.

The promise of services exhibits a powerful pull on manufacturers that want to remain competitive in the digital age. Rather than simply selling an industrial machine for a one-time fee, for example, machine builders can offer a product that-once connected within the plant or, ultimately, across an ecosystem — can be offered as a service in a recurring revenue model. In addition, by virtue of being connected, the machine's performance and utilization data can enable new value-added offerings, including predictive maintenance, quality control, plant-floor efficiency, and customer engagement.

Many manufacturers struggle with the transition to services due to the immediate prospects of service revenue being smaller than those of traditional product offerings. They want the flexibility to leverage both CapEx and OpEx; but in order to achieve this, they need to diversify.

Moreover, the top goals of European manufacturers in pursuing a service-oriented revenue model are focused on enhancing current businesses by reducing production costs and improving productivity, and on deepening relationships with existing customers. These are, of course, laudable and important goals. However, they do not reflect the opportunity to pursue new growth opportunities. The opportunity to generate significant new growth rests upon the agility and insights that come with digitzation.
Overall, the move from products to services is driving what could be called a "two-front war" in manufacturing - in effect, trying to maintain existing quality standards while at the same time moving into unexplored realms.

At the core of these challenges is the fact that manufacturers are not themselves "technology companies"; yet, services increasingly demand they must be. As General Electric CEO Jeffrey Immelt has stated, "All companies need to become Internet and software companies. The industrial world is changing dramatically, and those companies that make the best use of data will be the most successful.."[20]

Many European manufacturers are in the early stages of digitization and the transition to services. While some have begun to connect industrial machines on the plant floor, sharing data among makers, end users, third parties, and so forth is complex. One reason is a large percentage of proprietary protocols, which hinder interoperability

The challenges are clear to our European survey respondents. In their eyes, the No. 1 downside of services is greater dependency on third parties ( 32 percent), followed by complexity in product / service lifecycle management (30 percent) and difficulty in delivering services profitably (26 percent). In fighting a "two-front war" on both the product and service fronts, manufacturers will need to operate and share data across an expanded ecosystem of partners, thirdparty vendors, and so forth. Especially in Europe, many manufacturers are small and medium-sized enterprises that lack some of the broader digital capabilities that will be critical moving forward [22]. Partners and collaborators will assume an increasing role in solving the complexity.

Digital operating models provide more options when moving to an as-aservice model. These models require fundamental capabilities (analytics, compute at the edge, infrastructure/software/cloud) that allow organizations to continue evolving.

When we asked European end users and machine builderswhich technologies will have the greatest impact on production over the next three years, they cited digital capabilities such as cloud, 


\section{Tsvok, J. Toczynska}

analytics, and machine-tomachine (M2M) communications. As with our global totals, this is notable because of what respondents did not emphasize: "manufacturing" technologies such as robotics, 3D printing, and so forth. This underscores the pivotal role of digitization in manufacturing' sevolution, especially as connecting across an entire ecosystem-not justthe plant floor-becomes essential.

To further explore the impacts of digitization on capturing service value, we focused on one key manufacturing use case: connected machines on the plant floor. Connected machines can come in several different forms-devices monitored inhouse, devices monitored by a third party, or a new concept: "machine-as-a-service" (MaaS), in which the end-user manufacturer (that is, the customer) pays for a business outcome (for example, better uptime, improved production efficiency) as an operating expense, rather than buying a physical machine as a capital investment.

Predictive maintenance is a critical application enabled by connected machines and data analytics. It allows workforces to maintain the machines that need their attention most, anticipating breakdowns before they cause downtime.[23] In an industry in which original equipment effectiveness (OEE) metrics typically hover around 60 percent, such improvements promise truecompetitive differentiation.[24]

End-user manufacturers with access to predictive maintenance via connected machines highlighted the importance of digital technologies in maintaining uptime. Nevertheless, Europe lags behind global competitors once again.

Clearly, European manufacturers are interested in exploring use cases such as connected machines, but they also struggle with navigating operational complexities to capture value from services. Moreover, they risk being outpaced by global competitors that adapt and innovate faster.

To alleviate complexities such as the "twofront war," organizational silos, and a broader ecosystem of partners and third-party vendors, manufacturers must build a solid technology and business-process foundation. As long as the foundation is solid, they will have the flexibility to re-engineer their business based on digital capabilities and business models, as they extend theirsolutions beyond the plant floor across an extended ecosystem.

For many European manufacturing leaders, budgets are flat and additional technology investments can appear daunting. Digital transformation, however,requires a "save to invest" strategy. Increases in plant uptime, business agility, and customer engagement will offset initial costs. For example, Cisco research on enabling digital architectures found that such investments would drive 20 percent savings on IT costs, which could be deployed elsewhere in the business.[25] As we have seen in this study, an average digital manufacturer can drive a 12.8 percent profit gain projected over three years. The real cost is in not transforming.

Digital business transformation will enable manufacturers to:

- Build a Hyperaware Organization: To implement competitive new business models, manufacturers will need agile IT architectures, hyperaware analytics, and overall business agility. That is, if they are to respond to customers and end users in real time, while ensuring quality and uptime with unprecedented standards of excellence. Security must be built-in at every step, across the entire network, not simply added piecemeal on an app-by-app basis.

- Make Informed Decisions: Manufacturers need to treat analytics as a core capability. All of that data generated by new connections will need to be transformed into insight.26 Manufacturers need to move from making machines to generating value by gaining insights from data. In the digital age, no one goes it alone. Data insights will need to be shared securely across an expanding ecosystem of partners, customers, and thirdparty vendors. Manufacturers will need a new model to orchestrate that dynamic ecosystem and derive insights from data mined from far-flung sources. This will require foundational business and IT capabilities. In short, if manufacturers don't first transform, they will fall far short in their efforts to become innovative, agile ecosystem players. 
- Execute Fast: The process of changing business models is a highly complex endeavor that cannot be achieved by facing these challenges on a piecemeal basis. Industrial machine builder and end-user manufacturer leaders will need to shift perspective from building an organization known only for reliability to that of an organizationunderpinned by data analytics-that is known for its speed and agility.27 Each firm will need the business process and technology foundation to drive business agility; this will in turn enable innovation and business-model change while breaking down silos between IT/OT and engineering/services. Organizationwide digital business transformation-powered by the right technology foundation-will enable the speed and business agility that allow firms to meet these challenges and outpace their competition.

\section{Conclusions and perspectives for further research}

Without looking at the service transition through the lens of digital business transformation, the efforts of manufacturers in this area will continue to falter. Technology change is critical, but it must be undertaken in concert with organizational change. That demands consistent policy and company culture, driven by top-down leadership from the C-suite and the board of directors. 28

Organizations that transform will experience a new era of innovation, with concrete gains in uptime, safety, energy savings, and customer engagement. By driving organization-wide digital business transformation, the winners will leave the service dilemma—and their competitors—behind.

\section{References}

1. "European Manufacturing a 'Powerful Engine for Growth'," The Parliament, September 2014

2. "Top 5 Manufacturing Economies: What Challenges are They Facing?" Euromonitor International, September 2014

3. 'Made in Germany' Lies in the 'Gutter' After Volkswagen Caught Cheating," Telegraph, Sept. 21, 2015

4. "Italy Outlook: New Challenges," Moody's Analytics, October 2015
5. 'France 'Stuck in the Doldrums' with Second Worst Factory Sector in the Eurozone," The Telegraph, September 2015

6. "U.K. May Not Be A Manufacturing Powerhouse Anymore, But Here's Why Our Economy Can Still Thrive," The Telegraph, September 2015

7. "U.K. Manufacturers Urge George Osborne to Maintain Spending on Innovation," The Guardian, November 2015

8. Our survey respondents included 81 percent end-user manufacturers and 19 percent original equipment manufacturers.

9. "What Is Industrie 4.0 and What Should CIOs Do About It?" Gartner, May 2015

10. "Harnessing Digital Innovation for Enhanced Customer Service," Tata Consultancy Services, 2014

11. "Bringing Production and Services Together," Tim Baines, Sunday Times Magazine, January 2014

12. "Digital Vortex: How Digital Disruption Is Remaking Industries," Global Center for Digital Business Transformation, June 2015

13. "The Rolls Royce of Effective PerformanceBased Collaboration," Maintenance Technology, June 2012

14. “Rolls-Royce: Britain's Lonely High Flyer," The Economist, January 2009

15. "The Ubiquity Shift: Smart Systems Disruption," Harbor Research, 2013

16. "Overcoming the Service Paradox in Manufacturing," European Management Journal, December 2004

17. "7 Things to Know About the Internet of Things and Industrie 4.0," Moder Machine Shop, September 2015

18. "Digital Vortex: How Digital Disruption Is Remaking Industries," Global Center for Digital Business Transformation, June 2015

19. Cisco defines "Value at Stake" as the potential bottom-line value (higher revenues and lower costs) that can be created or will migrate among companies and industries based on their ability to harness digital technologies.

20. "GE CEO Says Software, Analytics Are Path To Zero Unplanned Downtime," GE Automation News, October 2014

21. "7 Things to Know About the Internet of Things and Industrie 4.0," Moder Machine Shop, September 2015

22. "Global Manufacturing Outlook: Performance in the Crosshairs," KPMG, 2014 


\section{Tsvok, J. Toczynska}

23. "GE Says Internet Connected Machines Are No Threat to Human Workers," VentureBeat, October 2013

24. "Overall Equipment Effectiveness," Maintenance Assistance, 2015

25. "Fast IT: Accelerating Innovation in the Internet of Everything Era," Cisco, 2014
26. Ten Ways Big Data Is Revolutionizing Manufacturing” Forbes, November 2014

27. "A New Go-To-Market Model for the Industrial Internet," Industry Week, October 2015

28. "Take Digital to the Core: Harness Three Forces To Win in Digital Business," Gartner, September 2015 